\title{
BMJ Open Interventions to improve infant and young child feeding practices in Ethiopia: a systematic review
}

Kedir Y. Ahmed (D) ,1,2 Kingsley Emwinyore Agho, ${ }^{2,3,4}$ Andrew Page, ${ }^{2}$ Amit Arora, ${ }^{2,3,5,6,7}$ Felix Akpojene Ogbo, ${ }^{2,8}$ on behalf the Global Maternal and Child Health Research collaboration (GloMACH)

To cite: Ahmed KY, Agho KE, Page A, et al. Interventions to improve infant and young child feeding practices in Ethiopia: a systematic review. BMJ Open 2021;11:e048700. doi:10.1136/ bmjopen-2021-048700

- Prepublication history and additional supplemental material for this paper are available online. To view these files, please visit the journal online. (http://dx.doi.org/10.1136/ bmjopen-2021-048700)

Received 05 January 2021 Accepted 30 July 2021

Check for updates

(C) Author(s) (or their employer(s)) 2021. Re-use permitted under CC BY-NC. No commercial re-use. See rights and permissions. Published by BMJ.

For numbered affiliations see end of article.

Correspondence to

Kedir Y. Ahmed;

kedirymam331@gmail.com

\section{ABSTRACT}

Objective In Ethiopia, despite the implementation of several interventions to improve infant and young child feeding (IYCF) practices, no published studies have highlighted the most effective IYCF interventions in the country. This systematic review investigated the impacts of various interventions on IYCF in Ethiopia.

Source of information A systematic search was conducted on seven computerised bibliographic databases (Embase, ProQuest Central, Scopus, PsycINF0, Web of Science, MEDLINE/PubMed and CINAHL) to locate experimental or quasi-experimental studies published between the year 2000 and May 2021.

Study eligibility criteria Interventional studies that measured IYCF indicators (early initiation of breast feeding (EIBF), exclusive breast feeding (EBF), the introduction of complementary foods, minimum dietary diversity (MDD), minimum meal frequency (MMF) and minimum acceptable diet) as outcome variables were included.

Study appraisal and synthesis All included studies were examined for biases related to interventional studies (ie, selection bias, performance bias, attrition bias, detection bias and reporting bias). Author reports of effect size measures were used to narratively report the findings of each study.

Results Of the 23 eligible studies, 14 studies were quasiexperimental and 9 studies were cluster randomised trials (CRTs). Eight quasi-experimental studies had a serious risk of bias, while two CRTs had a high risk of bias. Four studies for EBF and six studies for EIBF showed significant impacts of policy advocacy, health service strengthening, interpersonal communication, community mobilisation and mass media campaigns. Six studies for MDD and three studies for MMF indicated significant effects of community-level and health facility complementary feeding promotions on infants and young children. Interventions that delivered in combination increased the impacts in improving EIBF, MDD and MMF compared with a single intervention.

Conclusion Our review showed that 12 out of 21 eligible studies that implemented in the form of community-level and health facility interventions improved EIBF, EBF, and/or MDD in Ethiopia.

Protocol registration number PROSPERO, CRD42020155519.
Strengths and limitations of this study

- A meta-analysis was not conducted due to the wide heterogeneity of the study designs and outcome measures.

- This review was limited by the incompleteness of information from the individual studies (however, the study authors were contacted for information when necessary).

- Despite the limitations, the application of multiple search strategies in consultation with the medical librarian and registration of the systematic review protocol can be considered as strengths of this review.

\section{INTRODUCTION}

Appropriate infant and young child feeding (IYCF) improves childhood growth (through reduced risk of diarrhoea and respiratory infections as well as improved nutrition), ${ }^{1-7}$ increases the intellectual capacity of children $^{48}$ and reduces the risk of mothers experiencing diabetes mellitus, overweight and obesity. ${ }^{49}$ Promoting appropriate IYCF using evidence-based interventions is essential to protect and support maternal knowledge, beliefs and confidence in IYCF practices. ${ }^{10-13}$ Community-based and facility-based interventions that range from direct support and education to mothers and families on appropriate IYCF behaviours to training of health professionals can significantly improve IYCF behaviours. ${ }^{14-16}$

Global efforts to improve maternal IYCF behaviours have increased in the past three decades. These efforts included the International Code of Marketing of Breast-milk Substitutes ${ }^{17}$; the Innocenti Declaration ${ }^{18}$; the Baby-Friendly Hospital Initiative $(\mathrm{BFHI})^{19}$; the Millennium Development Goals $(\mathrm{MDGs})^{20}$; and more recently, the Global Nutrition Targets $2025^{21}$ and the Sustainable Development Goals (SDGs). ${ }^{22}$ The WHO 
and United Nations Children's Fund (WHO/UNICEF) have played major roles in driving these initiatives, which aimed to protect, promote, and support breast feeding and child nutrition. ${ }^{19}$ For example, the WHO Global Nutrition Targets (WHO GNT, including Targets 1 and 5) aim to reduce the global number of under-5 children who are stunted by at least $40 \%$ and increase the exclusive breastfeeding (EBF) rate to at least $50 \%$ by the year 2025 , respectively. However, most subnational areas of many African countries (including Ethiopia) are not on track to achieve WHO GNT goal- $5 .{ }^{23}$

In Ethiopia, while both government and nongovernmental organisations have implemented various maternal and child health-related policy interventions over the last two decades to increase infant feeding, ${ }^{24-26}$ a recent study has revealed that early initiation of breastfeeding (EIBF) prevalence was $75.5 \%$ and that for EBF was $59.9 \%,{ }^{27}$ with a wide heterogeneity across subnational areas of the country. ${ }^{23}$ These rates are well below the Ethiopian Health Sector Transformation Plan (HSTP) target of $90 \%$ and $72 \%$, respectively. ${ }^{25}$ Additionally, the proportion of children who met minimum dietary diversity (MDD) and minimum meal frequency (MMF) was $7.1 \%$ and $43.6 \%$, respectively. ${ }^{28}$ In Ethiopia, more than five million children were stunted in $2016,{ }^{29}$ and this is a major public health issue that is largely attributable to inappropriate IYCF.

To date, no previously published studies have examined the most effective IYCF interventions in the Ethiopian context. A detailed understanding of the specific types of interventions that can be implemented to improve IYCF in Ethiopia is essential, to specifically guide the allocation of scarce resources and the provision of targeted strategies to increase childhood feeding. This information will also be helpful in scaling-up and/or improve on current and future IYCF interventions in the country. Data from the assessment of relevant IYCF interventions would be crucial to stakeholders as Ethiopia implements national nutrition efforts (eg, HSTP) ${ }^{25}$ and global health programmes such as the Sustainable Development Goal, SDG-2.2, to end all forms of malnutrition. ${ }^{22}$ Accordingly, this systematic review investigated the impacts of community-based and facility-based interventions in improving IYCF practices of mothers/caregivers with children under 2 years of age in Ethiopia.

\section{MATERIALS AND METHODS}

Our review adhered to the 2009 Preferred Reporting Items for Systematic Reviews and Meta-Analyses (PRISMA) guidelines ${ }^{30}$ (online supplemental file 1), and the protocol for the review was registered in PROSPERO (International Prospective Register of Systematic Reviews, CRD42020155519). ${ }^{31}$

\section{Eligibility criteria}

Studies were included if they meet the following criteria: (1) experimental or quasi-experimental study design (including randomised controlled trials (RCT), nonRCTs, before and after studies, and interrupted time-series studies) with or without comparison groups or cluster; (2) conducted among pregnant women and mothers living with alive children under 2 years to improve IYCF practices; (3) used any type of IYCF interventions delivered between the antenatal period and 24 months' postpartum; (4) measured at least one core IYCF indicator such as EIBF, EBF, the introduction of solid, semi-solid and soft foods, continued breast feeding at 1 year, MDD, MMF and minimum acceptable diet (MAD); (5) were published in the English language and (6) conducted in Ethiopia from the year 2000 to date. We considered studies published over this period to demonstrate the impacts of the specific IYCF interventions in the context of Ethiopia to reflect the implementation of relevant global health programmes, including the MDGs and the current SDGs. ${ }^{23}$

The intervention strategies considered in this review focused on those performed at both facility and community levels. The interventions included nutritional education and counselling, interpersonal communication, mass media campaigns, nutrition-sensitive agricultural activities, group demonstration sessions and strengthening of health facilities.

Studies conducted among mothers with health problems such as HIV/AIDS and children with cleft palate were excluded.

The IYCF practices included EIBF, EBF, the introduction of solid, semi-solid and soft foods, continued breast feeding at 1 year, MDD, MMF and MAD, measured according to the WHO definitions for assessing IYCF indicators. ${ }^{32}$ These indicators were selected based on their effect on the health and development of infants and young children ${ }^{11} 1233$ and the evidence from previously published systematic reviews. ${ }^{1134}$

- EIBF was defined as the proportion of children aged 0-23 months who commenced breast feeding within the first hour of birth.

- EBF was defined as the proportion of infants 0-5 months of age who were fed no other food or drink, not even water, except breast milk (including milk expressed or from a wet nurse), but allows the infant to receive oral rehydration salt (ORS), drops and syrups (vitamins, minerals and medicines).

- Continued breastfeeding at 1 year was defined as the proportion of children 12-15 months of age who are fed breast milk.

- Introduction of complementary foods (solid, semisolid and soft foods) was defined as the proportion of infants 6-8 months of age who received solid, semisolid or soft foods in the previous 24 hours, during the day and at night.

- MDD was defined as the proportion of children 6-23 months of age who received foods from four or more of the seven food groups. The seven food groups included grains, roots and tubers; legumes and nuts; dairy products (milk, yoghurt, cheese); flesh foods 
(meat, fish, poultry and liver/organ meats); eggs; vitamin-A-rich fruits and vegetables; and other fruits and vegetables.

- MMF was defined as the proportion of breastfed and non-breastfed children 6-23 months of age, who received solid, semisolid or soft foods (including milk feeds for non-breastfed children) the minimum number of times or more (ie, two times for breastfed infants aged 6-8 months, three times for breastfed children aged 9-23 months and four times for nonbreastfed children aged 6-23 months, on the previous day).

- MAD was defined as the proportion of children 6-23 months of age who received both MDD and MMF.

\section{Information sources and search strategy}

Consistent with previously published systematic reviews, ${ }^{15} 35$ a three-stage search strategy was applied to locate both published and unpublished studies. In stage 1 , a manual search of previously published systematic reviews and the reference lists of all the eligible studies was performed to check for systematic reviews of interventions on IYCF in Ethiopia. In stage 2, index terms (eg, medical subject headings (MeSH) for Medline) and key terms were generated using the identified articles from the initial search for the full search strategy. In stage 3, a full search strategy was conducted on seven computerised bibliographic databases (Embase (OVID), ProQuest Central, Scopus, PsycINFO (EBSCO), Web of Science, MEDLINE (OVID)/PubMed and Cumulative Index to Nursing and Allied Health Literature (CINAHL)/ (EBSCO) to locate published studies, and secondary searching of OpenGrey and Grey Literature Report was conducted to locate unpublished works. The Population Intervention Comparator Outcome (PICO) criteria were used to devise the review question and related search terms. A combination of specified MeSH terms and keywords was drafted with some assistance from our institution-based medical librarian. The search strategy, including all identified index and keywords terms, was slightly adapted for each of the information sources. All electronic searches were conducted for eligible studies published between the year 2000 and May 2021. A full electronic search strategy developed for the Embase (OVID) is provided as online supplemental files 2 and 3.

The overall list of search terms used included:

\section{Term 1 (population)}

child, infant, newborn, baby, neonate, perinatal, postnatal, kid, toddler, young child, paediatric, mother, female, women, and caregiver

\section{Term 2 (interventions)}

- Education and counselling. breastfeeding promotion, breastfeeding support, breastfeeding education, health education, health promotion, nutrition education, food education, parent education, mother education, counselling, and nutritional counselling
- Social behavioural change communication: health behaviour, health-related behaviour, behaviour change, communication, interpersonal communication, information education communication, behaviour change communication (BCC), social change, social movement, social mobilisation, social behaviour, social network, peer group, advocacy, advocacy group, mass communication, mass media, print media, mobile phone, mHealth, eHealth, internet, radio, social media, television, text message and social market

- Community-based approaches: baby-friendly community initiative, community programme, community project, home visit, community health action, community health service, community healthcare, community intervention, community engagement, community leader, community mobilisation, demonstration, cooking demonstration, community roleplay, model breastfeeding community, community health worker and health extension worker

- Facility-based approaches: maternal care, child healthcare, child health service, paediatric healthcare, neonatal care, newborn care, rooming-in-care, newborn nursery, essential nutrition action, caregiver contact, baby-friendly hospital initiative, BFHI, antenatal care, postnatal care, Kangaroo care and skin-toskin contact

- Intervention designs: effectiveness, impact, evaluation study, programme evaluation, healthcare programme, project, health project, experimental study, interventional study, quasi-experimental study, randomised controlled trial, clinical trial, cluster-randomised trial, time-series study, control, placebo, comparison, and usual care

Term 3 (context)

Ethiopia

Term 4 (outcomes)

Infant and young child feeding, breast feeding, early initiation of breast feeding, timely initiation of breast feeding, exclusive breast feeding, breast milk substitute, complementary food, complementary feeding, weaning, introduction of complementary food, baby food, infant feeding, child feeding, meal, dietary diversity, meal frequency, child nutrition, infant nutrition, nutritional supplement, dietary supplement, lactation, and nursing

\section{Study selection}

Following the full search, all articles retrieved from the search databases were exported to EndNote X9 (Clarivate Analytics, USA) for removing duplicates, screening and selection. Titles and abstracts were screened by two reviewers (KYA and FAO) independently for assessment against the inclusion criteria. Potentially relevant articles that were selected in the first screening phase were retrieved in full and their citation details imported into the Joanna Briggs Institute System for the Unified Management, Assessment and Review of Information (JBI 


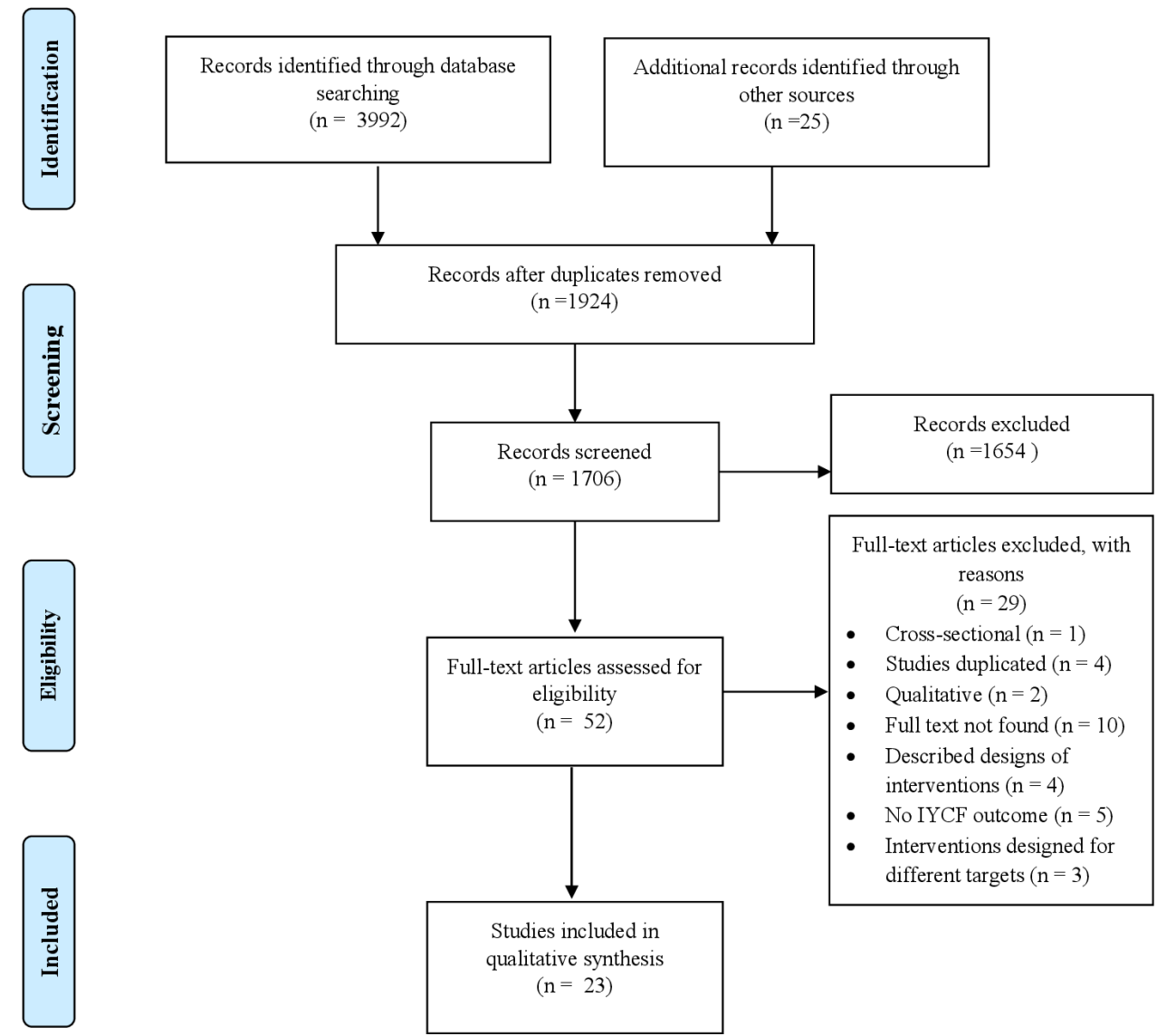

Figure 1 Preferred Reporting Items for Systematic Reviews and Meta-analyses (PRISMA) flowchart for selection of eligible studies. IYCF, infant and young child feeding.

SUMARI). Full texts of the included studies were read and checked by two independent reviewers (KYA and FAO) against the eligibility criteria. Studies that did not meet the eligibility criteria were excluded and reasons for the exclusion of studies were recorded and reported in the systematic review. Any disagreements between the two independent reviewers were resolved by consensus and arbitration by the third (KEA) author of the review. For studies with uncertainties regarding eligibility, the authors were contacted to seek additional information. A total of two contact attempts were made, and if no response was received, the articles were screened for eligibility based on the information available. The results of the study selection process are presented in a PRISMA flow diagram (figure 1).

\section{Data collection process and data items}

Relevant data were extracted from the eligible studies by KYA and independently verified by FAO using piloted forms adapted from the Joanna Briggs Institute (JBI) reviewer's manual ${ }^{33}$ and the Cochrane Pregnancy and Childbirth Group for Systematic Reviews. ${ }^{36}$ Eligible studies were identified using the following information: first author, publication year, study design and setting, study participants, sample size, geographical region, intervention components, location of intervention delivery, outcome measures, statistical analysis and results. Corresponding authors of eligible studies were contacted for information that was not clear in the data extraction. A total of two contact attempts were made, and if no response was received, only the information available was used.

\section{Risk of bias assessment}

All included studies were examined for the five types of biases of interventional studies: (1) selection bias; (2) performance bias; (3) attrition bias; (4) detection bias and (5) reporting bias. KYA and KEA independently conducted the risk of bias assessment using the revised Cochrane risk of bias tool for clustered randomised trials (ROB 2.0) ${ }^{37} 38$ and the risk of bias in non-randomised studies-of interventions (ROBINS-I) tool ${ }^{39}$ for assessing the risk of bias in quasi-experimental studies. Cluster randomised trials were assessed for five domains (ie, randomisation and identification or recruitment bias, deviations from intended interventions, missing data, measurement of outcomes and selection of reported result), and quasi-experimental studies were assessed for seven domains (ie, confounding, selection of participants, classification of interventions, deviations from intended interventions, missing data, measurement of outcomes and selection of reported result). For cluster randomised trials, the overall risk of bias judgement included low risk, some concerns and high risk, ${ }^{37} 38$ and 
for the quasi-experimental studies, the overall risk of bias outcome included low, moderate, serious and critical risk of bias. ${ }^{39}$ There was no disagreement between reviewers in the risk of bias assessment, no third arbitrator was needed.

\section{Data synthesis}

Author reports of effect size measures were used in reporting the findings of each study. Effect size measures included a comparison between experimental and control groups (eg, OR), as well as the difference in proportion between preoutcome and postoutcome measures (eg, change in proportion). Where available, $95 \%$ CI and $\mathrm{p}$ value were obtained from the eligible studies. Based on published methodological studies, ${ }^{4041} 95 \%$ CI and $p$ value were calculated using the available information where the full text of the eligible studies did not report these estimates. Narrative methods including text, table and figure were also used as a tool for data presentation.

\section{Patient and public involvement}

There was no direct patient or public involvement in this review.

\section{RESULTS}

\section{Characteristics of eligible studies}

A total of 4017 articles were retrieved from the database and hand searching. Of these, 1924 were retained in the EndNote library after removing duplicates. Titles and abstracts of the articles were screened, and 1654 articles were removed. Full-text eligibility checks of the remaining 52 articles excluded 29 studies. The reasons for exclusion of studies included: 4 studies were duplicates, ${ }^{42-44} 1$ study was cross-sectional, ${ }^{45} 2$ studies used qualitative evaluation, ${ }^{46} 47$ 10 studies were abstracts, ${ }^{48-57} 4$ studies were based on the design and implementation of interventions, ${ }^{58-61} 5$ studies did not measure IYCF outcomes, ${ }^{62-70}$ and 3 studies were based on interventions designed for different target groups ${ }^{71-73}$ (figure 1).

Among the 23 included studies, 14 were quasiexperimentalstudies, ${ }^{74-87}$ while theremaining9 9 werecluster randomised trials. ${ }^{88-96}$ At least one interventional study was conducted in Southern Nations Nationalities and Peoples' Region (SNNPR), ,7-79 $818284-8690$ Oromia, ${ }^{74} 7778$ 83-88 9195 Amhara, ${ }^{76-7884-8789929395}$ Tigray $^{777984-8795}$ and Afar $^{80}$ regions, but we did not find published interventional studies conducted in either Addis Ababa and Dire Dawa city administrations, Harari, Benishangu1, Gambella, or Somali regions.

\section{Risk of bias in included studies}

Online supplemental files 4 and 5 present the risk of bias assessment of the included studies. Nine cluster randomised trials were assessed for risk of bias using the Cochrane RoB 2.0 tool. Overall, studies by Muluye et al, ${ }^{94}$ and Passarelli $e t a \ell^{55}$ judged as high risk of bias, while studies by Abdulahi et $a \ell^{91}$ and $\operatorname{Kim}$ et $a l^{89}$ had a low risk of bias. Two cluster randomised studies had a high risk of bias in the domains for randomisation. ${ }^{94} 95$ Out of 14 quasi-experimental studies assessed using the ROBINS-1 tool, eight studies had a serious risk of bias ${ }^{74} 777881-8486$ and four studies had a moderate risk of bias. ${ }^{79} 808587$ The remaining two studies were judged as critical risk of bias. ${ }^{75} 76$ Seven out of 14 studies had a serious or critical risk of bias in the confounder adjustment, ${ }^{74-78} 81-83$ while 8 out of 14 studies had a low risk of bias in outcome measurement. ${ }^{77-81} 848587$

\section{Evidence from reviewed studies}

In the eligible studies, $n=23$, the majority of the interventions were provided in the form of BCC using nutrition education, ${ }^{81} 82929395$ community mobilisation, ${ }^{76} 788789$ health education materials ${ }^{7480} 828391$ and mass media communication. ${ }^{79} 89$ Other interventions were also provided in the form of peer/group support and training of mothers, ${ }^{91-93}$ promotion of chicken husbandry and home gardening, ${ }^{95}$ productive safety net programme (in-cash/food rations), ${ }^{84}$ strengthening of healthcare system, ${ }^{78} 80$ 85-87 training and supervision of healthcare providers, ${ }^{76} 7883$ and food preparation and practical demonstration sessions. ${ }^{81} 8288919496$ Additionally, two studies used the health belief model (HBM) as a mode of intervention delivery for $\mathrm{BCC}^{8190}$ (table 1).

Sixteen studies used control groups for comparison with experimental groups, ${ }^{78} 80-84$ 87-96 while seven studies did not use control or comparison group. ${ }^{74-77798586}$ Two studies used two experimental arms as an intervention group $^{90}{ }^{95}$ (table 1).

\section{Impact of interventions on IYCF practices in Ethiopia early initation of breast feeding}

Tables 1 and 2 are presented to summarise evidence from eligible studies. Eight studies reported the effect of interventions to improve EIBF. ${ }^{76} 77798085-8791$ A health facility level intervention in the Afar region that integrated nutrition information into health professional guidelines and also provided family education and counselling booklets resulted in a significant improvement in EIBF in the experimental group compared with the control group (OR=1.70; 95\% CI: 1.17 to $2.46 ; \mathrm{p}=0.005) .{ }^{80} \mathrm{Kim}$ et $a l^{79}$ showed that interventions delivered through advocacy and policy dialogues, interpersonal communication and community mobilisation, and mass communication improved EIBF. This study also showed that the association between exposure to two or more types of interventions and improvement in EIBF was stronger compared with exposure to a single type of intervention $(\mathrm{OR}=2.07$; 95\% CI: 1.09 to $3.91 ; \mathrm{p}<0.05$ for multiple intervention vs $\mathrm{OR}=1.88$; $95 \% \mathrm{CI}: 1.08$ to 3.27 ; $\mathrm{p}<0.05$ for single intervention). ${ }^{79}$

Karim et $a l^{86}$ indicated that supporting community health workers decision-making using community health data improved EIBF (OR=1.27; 95\% CI: 1.10 to 1.46; $\mathrm{p}=0.001)$. However, Wereta et al, 2018 reported no significant effect of community-based maternal and 


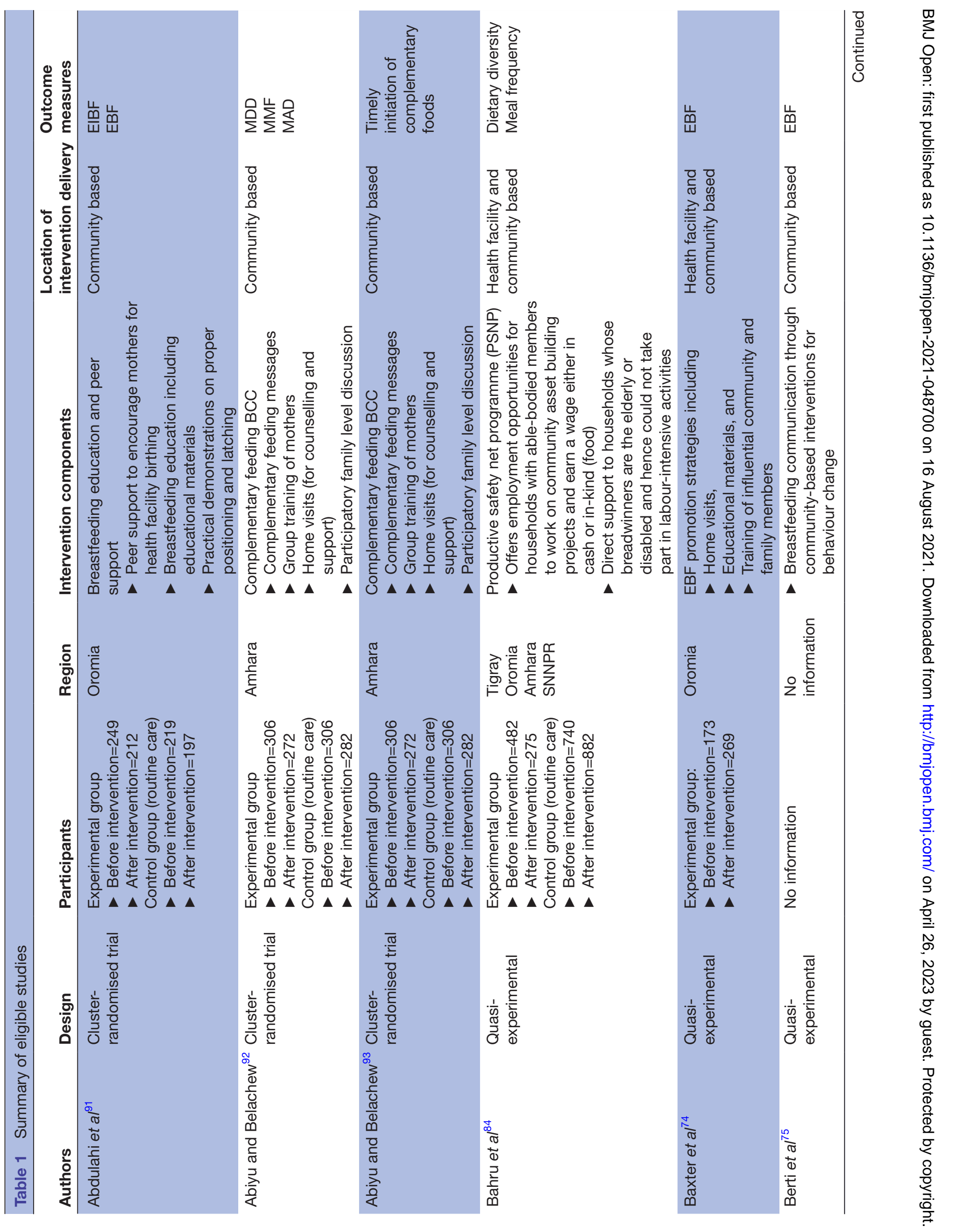




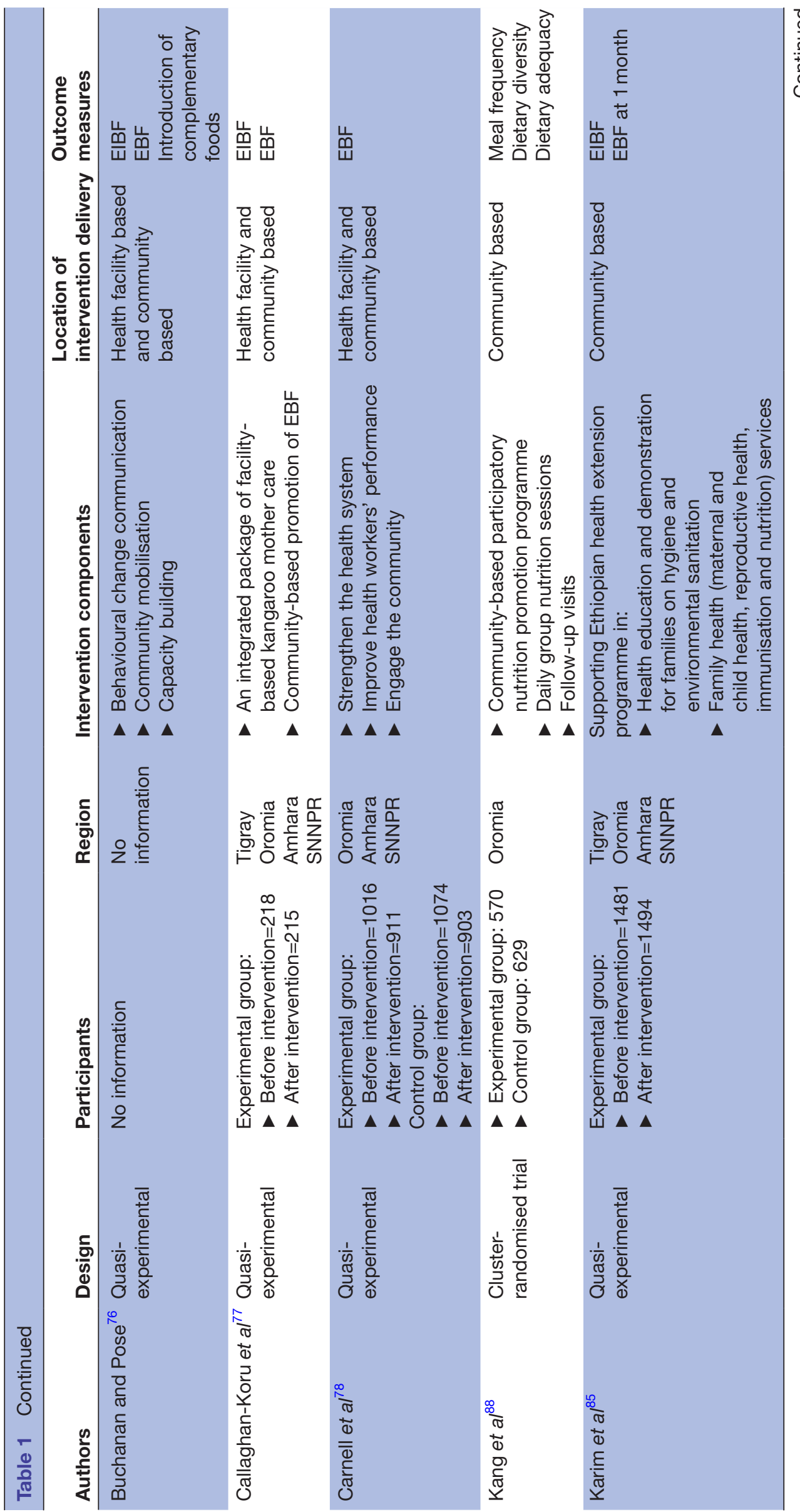




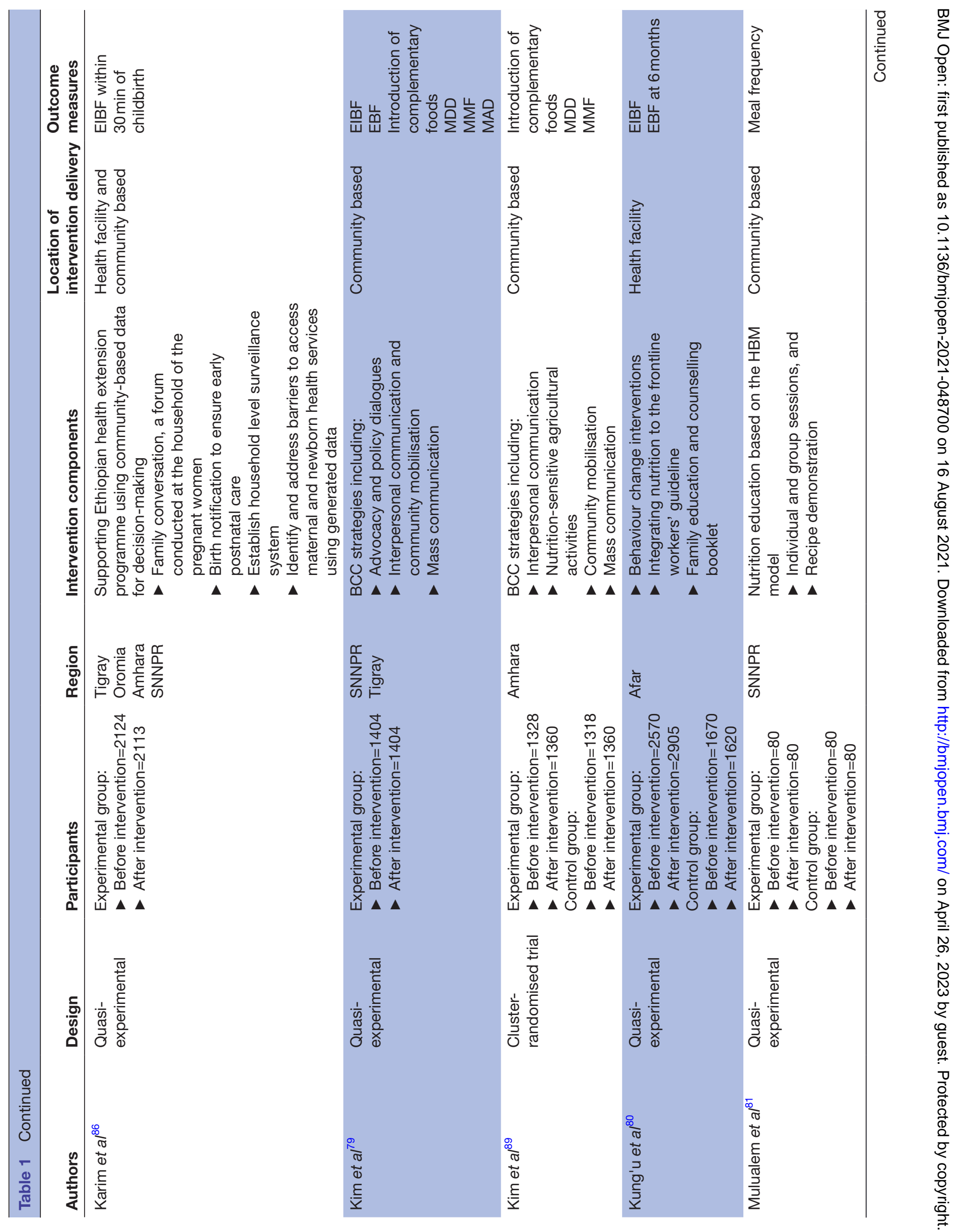




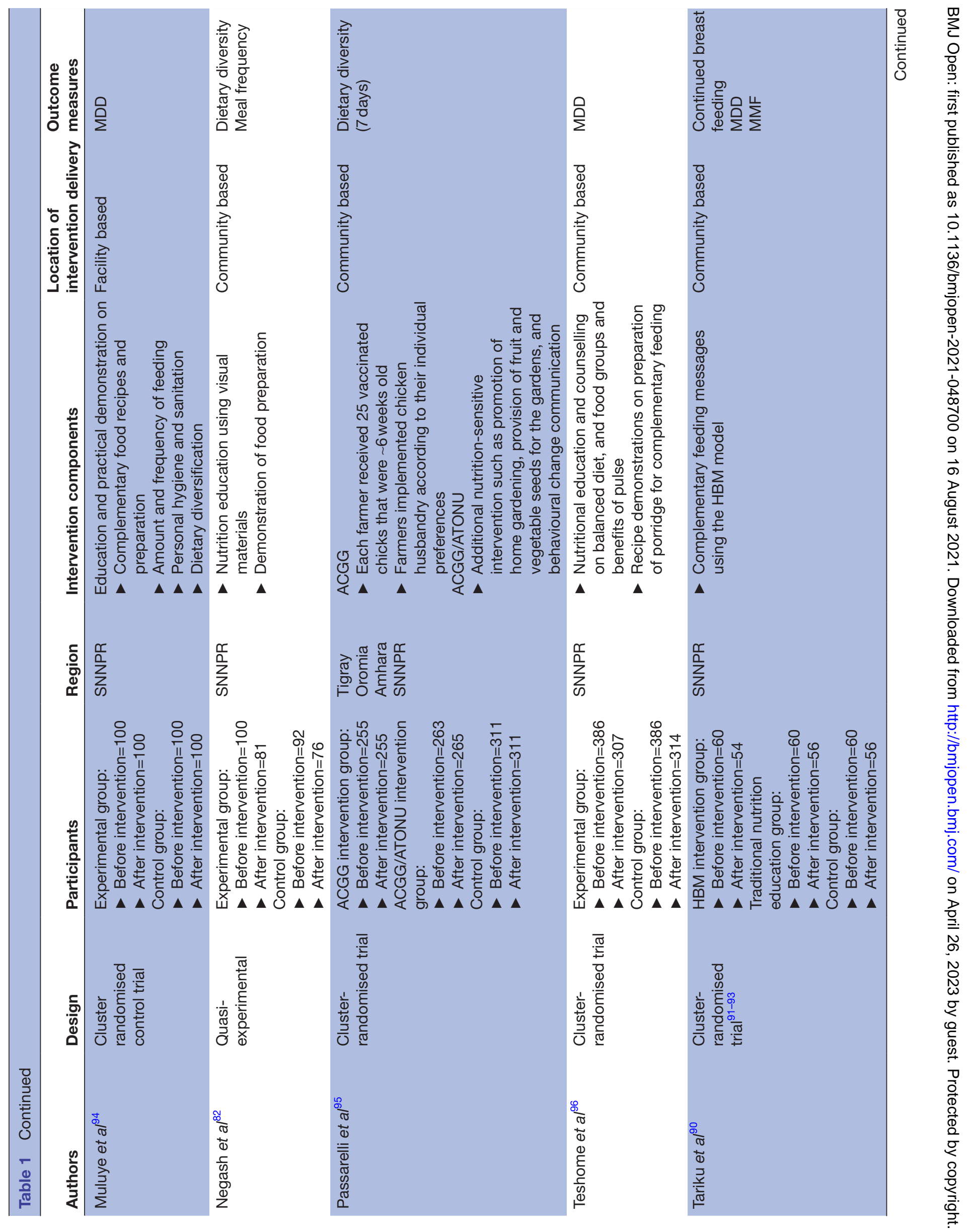




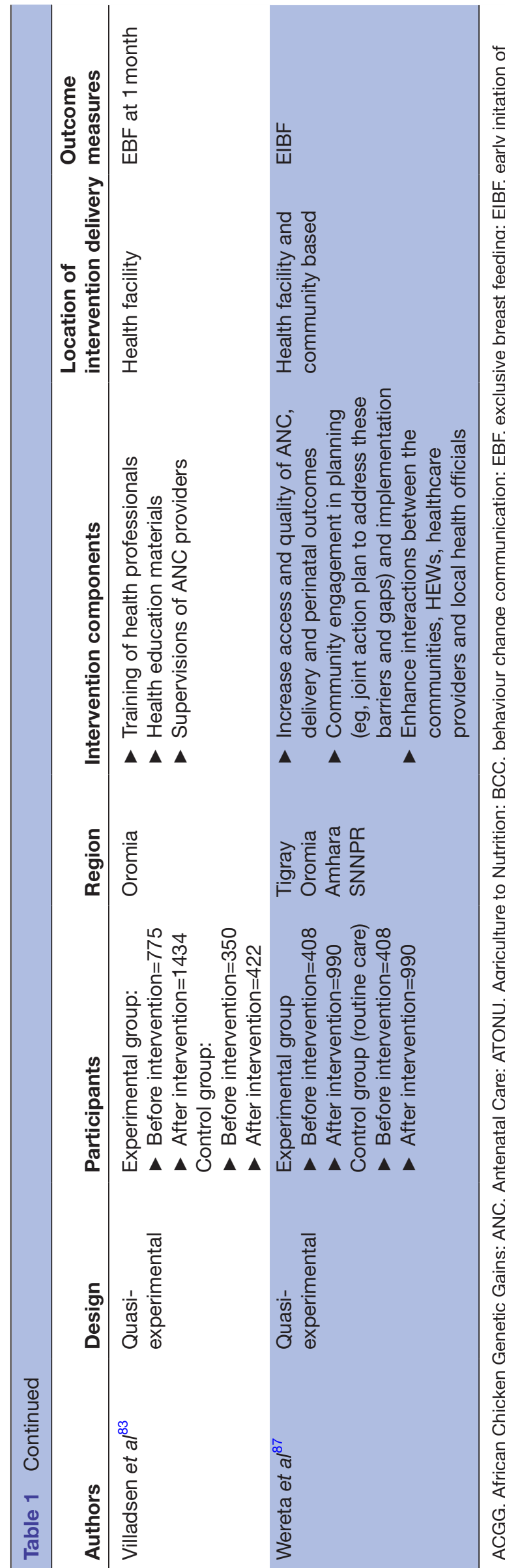
child health service quality improvement project on EIBF
(average treatment effect (ATE) $=2.8 ; 95 \% \mathrm{CI}:-4.7$ to
竞 $10.6 ; \mathrm{p}=0.468$ ).

Buchanan and Pose,${ }^{76}$ Callaghan-Koru et $a l^{77}$ and Karim $e t a l^{85}$ found an increase in the proportions of EIBF (from $31.0 \%$ to $77.0 \%, 51.4 \%$ to $67.9 \%$, and $46.0 \%$ to $54.2 \%$, respectively), following the implementation of BCC and community-level health programmes including breastfeeding promotions and family health services.

\section{Exclusive breast feeding}

Ten studies reported the effect of interventions on EBF in Ethiopia. ${ }^{74-80} 838591$ Of these, eight studies measured EBF for up to 6 months, ${ }^{74-8091}$ while two studies measured EBF for up to 1 month. ${ }^{83} 85$ Villadsen $e t a l^{83}$ found that antenatal care strengthening for pregnant women significantly improved EBF in health facilities under intervention compared with health facilities without intervention ( $\mathrm{OR}=2.30 ; 95 \% \mathrm{CI}$ : 1.40 to $3.60 ; \mathrm{p}=0.005)$. Integrating nutrition into the health workers' guidelines, and providing family education and counselling booklet (OR=2.62; 95\% CI: 0.95 to $7.21 ; \mathrm{p}=0.062),{ }^{80}$ and exposure to BCC intervention (ie, advocacy and policy dialogues, interpersonal communication and community mobilisation and mass communication) $(\mathrm{OR}=1.51 ; 95 \% \mathrm{CI}: 0.95$ to $2.40 ; \mathrm{p}>0.050)^{79}$ did not affect EBF behaviours.

Seven studies showed that there were increases in EBF during the intervention period, ${ }^{74-78} 8591$ but out of these studies, two indicated that improvements in EBF were not statistically significant. ${ }^{74} 78$ Abdulahi $e t$ a ${ }^{91}$ reported a significant difference in the proportion of EBF between the intervention $(68.3 \%)$ and control groups $(54.8 \%)$ $(\mathrm{p}<0.001)$, following the interventions of peer support, breastfeeding education and practical demonstration sessions on positioning and attachment. Studies by Callaghan-Koru et al $(\mathrm{p}<0.010)^{77}$ and Karim et al $(\mathrm{p}<0.001)^{85}$ documented that implementing communitybased and health facility interventions improved EBF, but the remaining two studies on EBF did not report the statistical test of significance. ${ }^{748}$

Introduction of solid, semi-solid and soft foods

Four studies reported the effect of different types of BCC interventions on the introduction of complementary foods. ${ }^{76} 798993$ BCC interventions using complementary feeding messages, training of mothers in groups, counselling and support at home level and facilitating participatory family discussion were effective in improving the timely initiation of complementary foods $(\mathrm{RR}=2.60$; 95\% CI: 1.78 to $5.86 ; \mathrm{p}=0.002) .{ }^{93} \mathrm{Kim}$ et $a l^{79}$ investigated the effect of exposure to BCC interventions (advocacy and policy dialogues, interpersonal communication and community mobilisation and mass communication) on the introduction of solid, semi-solid and soft foods in two separate arms. The first arm of the study found an increase in the proportion of infants who were introduced to solid, semi-solid and soft foods (from $37.4 \%$ to $59.7 \%, \mathrm{p}<0.001)$. In contrast, the second arm of the study 


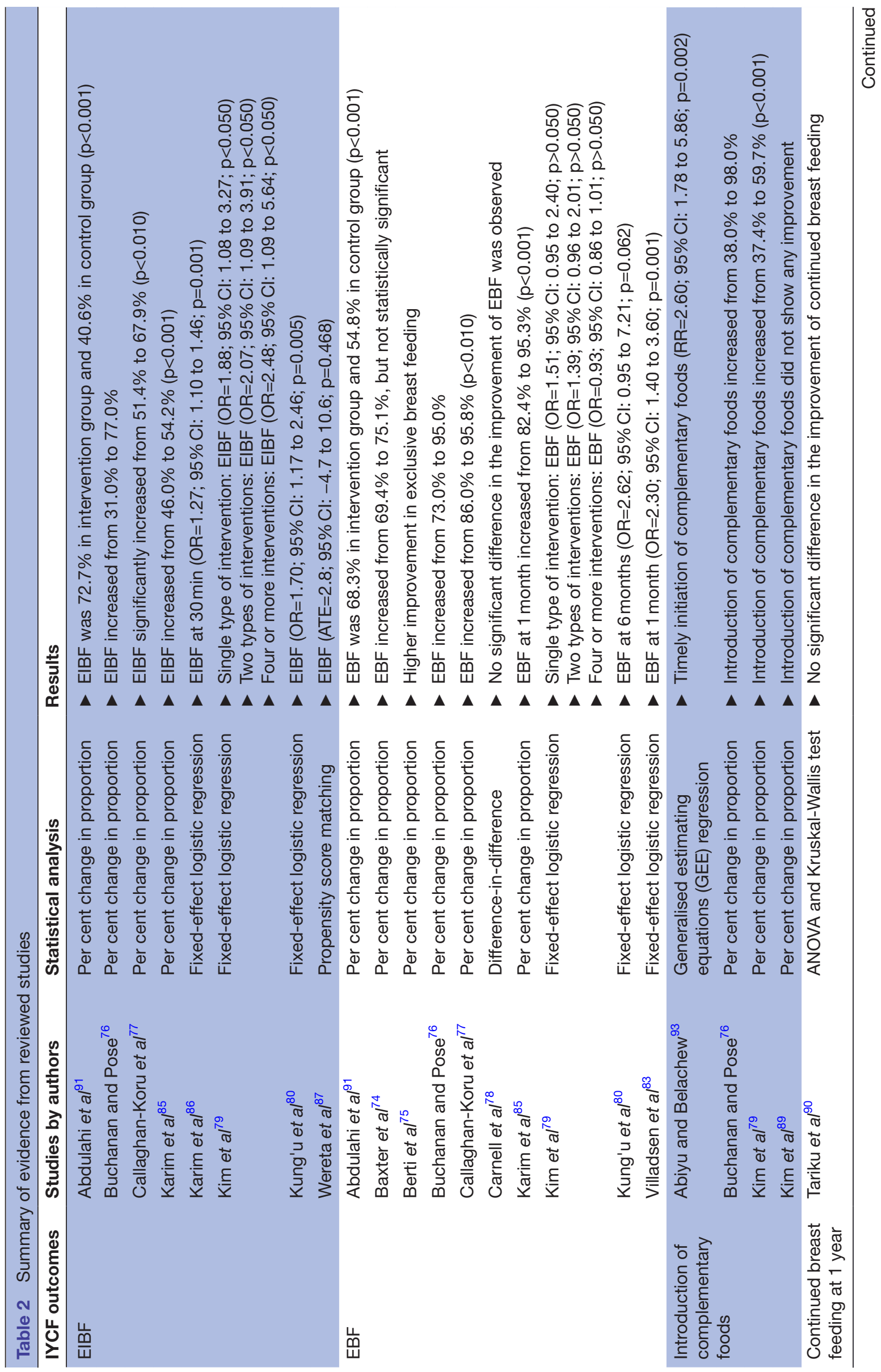




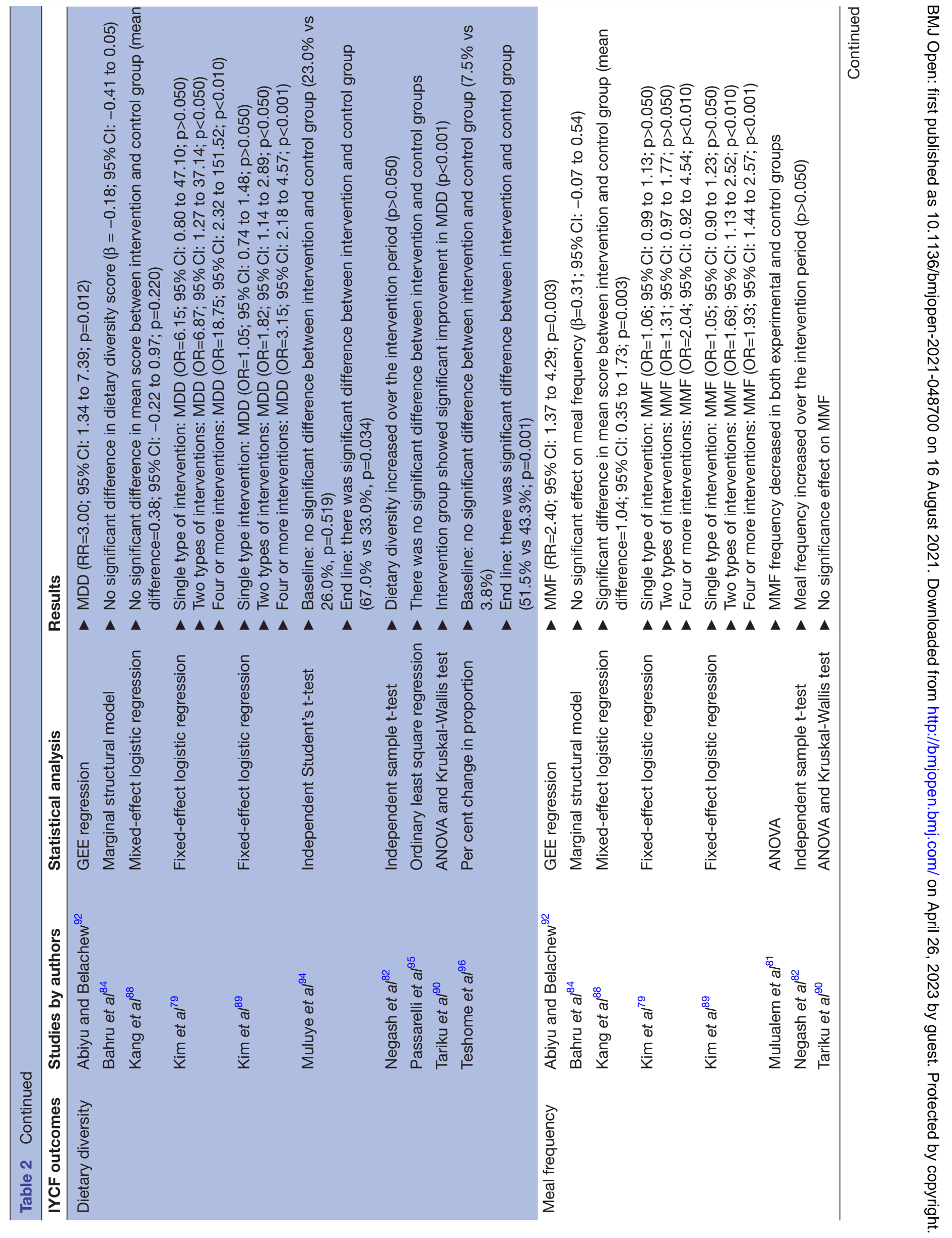


did not find a significant improvement (from $58.7 \%$ to $61.3 \%, \mathrm{p}>0.05) .{ }^{89}$ The remaining study by Buchanan and Pose $^{76}$ showed improvement in proportion, but no test of significance was reported.

Continued breast feeding at 1 year

Only one study measured the impact of interventions on continued breast feeding at 1 year. Tariku et a $\theta^{0}$ showed that IYCF messages using the HBM did not impact the continued breastfeeding rate at 1 year.

\section{Minimum dietary diversity}

Ten studies reported the effect of interventions on MDD. ${ }^{79} 828488-909294-96$ Of these, six were measured according to the WHO definition for MDD, ${ }^{79} 8990929496$ while three studies used any four food groups as a cutoff point to measure MDD.$^{82} 848$ A study by Abiyu and Belachew $^{92}$ using BCC interventions including complementary feeding messages, mothers group training, home-based counselling and support, and participatory family discussion improved MDD for infants and young children ( $R R=3.00 ; 95 \%$ CI: 1.34 to $7.39 ; p=0.012$ ). Two studies by Kim $e t a l^{799}$ revealed the significant impacts of exposure to more than one type of BCC intervention (advocacy and policy dialogues, interpersonal communication and community mobilisation and mass communication) on MDD, but these studies showed that exposure to a single type of intervention did not have an impact on MDD. Tariku et a $\ell^{0}$ showed interventions involving complementary feeding messages using the HBM model significantly increased the proportion of MDD (from $37.5 \%$ to $67.9 \%$; $\mathrm{p}<0.05$ ).

End line survey results following the intervention of nutritional education and counselling, and recipe demonstrations by Muluye et al $(67.0 \% \text { vs } 33.0 \%, \mathrm{p}=0.034)^{94}$ and Teshome et al ( $51.5 \%$ vs $43.3 \%$; $\mathrm{p}=0.001)^{96}$ showed significant differences in the proportion of MDD between intervention and control groups. The remaining four studies indicated that the proportion of MDD increased over the intervention period, but the effect was not significant. $^{82848895}$

\section{Minimum meal frequency}

MMF was included as an outcome variable in eight interventional studies. ${ }^{79} 81828488-9092$ Four studies used the WHO definition for assessing MMF. ${ }^{79} 899092$ Complementary feeding BCC interventions using nutritional education and counselling, and recipe demonstration sessions improved MMF practice of mothers $(R R=2.40$; 95\% CI: 1.37 to $4.29 ; \mathrm{p}=0.003) .{ }^{92} \mathrm{Kim}$ et a $\mathrm{l}^{89}$ indicated that exposure to two types of BCC interventions (advocacy and policy dialogues, interpersonal communication and community mobilisation, and mass communication) had a significant effect on MMF of infants and young children compared with those who did not expose to intervention $(\mathrm{OR}=1.69 ; 95 \% \mathrm{CI}: 1.13$ to $2.52 ; \mathrm{p}<0.010)$. Kang et $a l^{88}$ found that interventions using a community-based participatory nutrition programme had significant impact on 
the mean score of MMF (mean difference $=1.04 ; 95 \% \mathrm{CI}$ : 0.35 to $1.73 ; p=0.003$ ). Except for one study, which did not do a test for significance, ${ }^{82}$ the remaining four studies did not show significant improvements in MMF. ${ }^{79} 818490$

\section{Minimum acceptable diet}

Out of three studies that measured MAD as an outcome, two studies used the WHO definition for assessing MAD,${ }^{79} 92$ while the remaining study calculated dietary adequacy indicator using a composite dietary diversity and meal frequency scores. ${ }^{88}$ Abiyu and Belachew ${ }^{92}$ implemented BCC interventions (including nutritional education and counselling, and recipe demonstration) to improve MAD. The result from this study showed the significant effect of interventions on MAD $(R R=2.70$; 95\% CI: 1.13 to $7.23 ; p=0.036)$. Community-based participatory nutrition programme by Kang et $a l^{88}$ reported significant effect of interventions on the dietary adequacy score (mean difference $=1.40 ; 95 \%$ CI: 0.49 to 2.32; $\mathrm{p}=0.003$ ). However, a study by Kim et $a l^{79}$ documented that implementing four or more type BCC interventions (advocacy and policy dialogues, interpersonal communication and community mobilisation, and mass communication) improved MAD (OR=14.29; 95\% CI: 2.23 to 90.28; $\mathrm{p}<0.010$ for $4+$ interventions) .

\section{DISCUSSION}

A total of 23 studies were included, and of these, 14 were quasi-experimental studies, ${ }^{74-87}$ and 9 were cluster randomised trials ${ }^{88-96}$ Four studies for $\mathrm{EBF}^{77838591}$ and six studies for $\mathrm{EIBF}^{777980858691}$ showed that community-based and facility-based interventions delivered in the form of BCC (such as policy advocacy, interpersonal communication, community mobilisation and mass media campaigns) and health service strengthening had an impact on infants. Two studies for the introduction of complementary foods, ${ }^{79} 93$ six studies for MDD ${ }^{79} 8990929496$ and three studies for $\mathrm{MMF}^{88} 8992$ indicated significant effects of BCC on infants and young children. Two eligible studies showed that combined interventions delivered in the form of interpersonal communication, nutrition-sensitive agricultural activities, community mobilisation and mass media campaigns had more impacts on EIBF, MDD, and MMF. $^{79} 89$

Global evidence indicates that BCC interventions (including policy advocacy, interpersonal communication, community mobilisation and mass media campaigns) are essential in promoting IYCF practices. These initiatives also create a supportive environment that helps mothers to adopt and sustain positive child feeding behaviours. ${ }^{1197}$ The main goals of BCC intervention include improving behaviours of facility-level and community-level health workers, mothers and other caregivers, and members of their households. ${ }^{1197}$ Our review showed that BCC interventions in the form of policy advocacy, interpersonal communication, community mobilisation and mass media campaigns improved EIBF,
MDD and MMF. Our finding is consistent with systematic reviews from lower-income and middle-income countries (LMICs), which indicated that group nutritional education and counselling, family or social support, integrated mass media coverage and community mobilisation were effective in improving IYCF practices. ${ }^{5}{ }^{11}$

Although BCC interventions promote skills and knowledge that are necessary for improving IYCF practices, studies from LMICs indicated that achieving the intended target is often challenging without complementary interventions that provide or facilitate material inputs. ${ }^{97-100}$ This could be due to the fact that child feeding decisions not only depend on the knowledge and perception of the mother but also are influenced by a complex interplay of factors, including available resources, partner support, mother's time and close family support. ${ }^{97-101}$ Affleck and Pelto $^{99}$ reported that a lack of money to provide diversified diet for infants and young children was a major barrier to improve appropriate IYCF behaviours among Bangladeshi women. Thus, promoting material inputs (such as cash transfer and provision of food materials) and/or non-material inputs (skills and knowledge) are required in achieving appropriate and sustained IYCF behaviours.

Research has shown that exposure to more than one IYCF intervention, delivered through different platforms (eg, community or facility based), was more successful in improving IYCF outcomes compared with a single form of intervention delivered at a single setting. ${ }^{5}$ Our review indicated that exposure to more than two types of interventions was associated with improvement in EIBF, MDD and MMF. ${ }^{79}{ }^{89}$ This result due to interventions delivered through multiple settings may have an increased intensity that can be translated to behavioural changes due to repeated contacts and adequate coverage of interventions. ${ }^{102}$ Our review suggests that interventions that aim to improve IYCF behaviours in Ethiopia should be delivered through different and specific types of contexts (including household, health facility and community) and should be provided along the continuum of care from conception until a child's second birthday.

In the past two decades, the Ethiopian government's commitment to improving IYCF has been consistent, and this started with the development of the National Strategy for IYCF in 2004 and followed by National Strategy for Nutrition in $2008,{ }^{24}{ }^{103}$ in line with the WHO/UNICEF IYCF strategy. ${ }^{104}$ In 2015 , the Ethiopian government launched the Health Sector Transformation Plan to improve health outcomes, including IYCF practices. ${ }^{25}$ Based on this initiative, many facility-based and community-based interventions have been implemented to protect, promote and support appropriate IYCF behaviours. ${ }^{11}$ Nevertheless, our review found that there has been no formal IYCF intervention conducted in Addis Ababa and Dire Dawa city administrations, and Harari, Benishangu1, Gambella and Somali regions. Our review suggests an expansion of additional experimental studies from successful subnational interventions 
implemented in Amhara, ${ }^{89} 9293$ Oromia $^{83} 8891$ and SNNP $^{9496}$ regions, to maximise the opportunities for the prevention of IYCF-related morbidity and mortality in those regions.

Additionally, our review did not find any studies which incorporated the use of mobile health (mHealth) as part of an intervention package for improving IYCF. ${ }^{105}$ Future experimental studies that consider the use of mHealth techniques are required, especially that previously published studies have shown the positive impacts of interventions (in the form of voice messages, SMS and phone calls) on IYCF practices. ${ }^{106-108}$ Finally, interventional studies that consider the role of fathers/partners as well as grandmothers in improving IYCF behaviours may be warranted in Ethiopia. ${ }^{101} 109110$

The present systematic review of IYCF outcomes from community-based and facility-based interventions (eg, BCC, health service strengthening, community mobilisations and nutrition-sensitive agricultural activities) has strengths and limitations. First, a meta-analysis was not conducted due to the wide heterogeneity of the design and outcome measures. Second, this review was limited by the incompleteness of information from the individual studies. Nevertheless, the study authors were contacted for information when it is necessary. Third, our search was limited to published studies in English, which exclude studies published with other languages. Fourth, lack of evidence and under-representation of some regions may limit the generalisability of our review. However, evidence from this review is potentially relevant for IYCF policy efforts in Ethiopia. Despite the above limitations, the application of multiple search strategies in consultation with the medical librarian and registration of the systematic review protocol can be considered as strengths of this review. Furthermore, future studies that consider the assessment of the full set of the updated IYCF indicators for all Ethiopian children would be warranted. ${ }^{111}$ This approach would ensure that both subnational and national and IYCF estimates are accurate and reliable and ensure that interventions and policy decisions in resource allocation are targeted at the most at-risk population. It would also ensure that IYCF programme monitoring and evaluation are consistent across all levels of government. $^{111}$

\section{CONCLUSION}

Our systematic review showed that 12 out of 21 eligible studies that implemented interventions in the form of policy advocacy, health service strengthening, interpersonal communication, community mobilisation and mass media campaigns reported improved EIBF, EBF and/or MDD in Ethiopia. The impacts of current and/or future interventions on IYCF practices in Ethiopia will be greater when interventions are combined, introduced and implemented along the continuum of care from conception until a child's second birthday.

\section{Author affiliations}

${ }^{1}$ Department of Public Health, Samara University, Samara, Afar, Ethiopia

${ }^{2}$ Translational Health Research Institute, Western Sydney University—Campbelltown

Campus, Campbelltown, New South Wales, Australia

${ }^{3}$ School of Health Sciences, Western Sydney University—Campbelltown Campus, Campbelltown, New South Wales, Australia

${ }^{4}$ African Vision Research Institute (AVRI), University of KwaZulu-Natal, Durban, South Africa

${ }^{5}$ Oral Health Services, Sydney Dental Hospital, Surry Hills, New South Wales, Australia

${ }^{6}$ Health Equity Laboratory, Campbelltown, New South Wales, Australia ${ }^{7}$ Discipline of Child and Adolescent Health, Faculty of Medicine and Health, Sydney Medical School, The University of Sydney, Westmead, New South Wales, Australia ${ }^{8}$ Barmera Medical Clinic (Lake Bonney Private Medical Clinic), Barmera, South Australia, Australia

\section{Twitter Kedir Y. Ahmed @KedirYAhmed}

Acknowledgements The authors are grateful to Lily Collison (Medical Librarian at Western Sydney University) for the time and help in designing the search strategy.

Collaborators GloMACH members are Kingsley E Agho; Felix Akpojene Ogbo; Kedir Yimam Ahmed; Thierno Diallo; Osita E Ezeh; Osuagwu L Uchechukwu'; Pramesh R Ghimire; Blessing Jaka Akombi; Pascal Ogeleka; Tanvir Abir; Abukari I Issaka; Abdon Gregory Rwabilimbo; Daarwin Subramanee; Nilu Nagdev; Mansi Dhami.

Contributors KYA conceptualised the study idea, performed the literature searching, selected the paper of interests, performed data extraction and critically revised the manuscript. AP and AA critically revised the manuscript for intellectual content. KEA performed the risk of bias assessment and critically revised the manuscript. FAO contributed to the conception of the research idea, selected the paper of interests, performed data extraction and critically revised the manuscript. All authors read and approved the final manuscript.

Funding The authors have not declared a specific grant for this research from any funding agency in the public, commercial or not-for-profit sectors.

Competing interests None declared.

Patient consent for publication Not required.

Provenance and peer review Not commissioned; externally peer reviewed.

Data availability statement Data sharing not applicable as no datasets generated and/or analysed for this study.

Supplemental material This content has been supplied by the author(s). It has not been vetted by BMJ Publishing Group Limited (BMJ) and may not have been peer-reviewed. Any opinions or recommendations discussed are solely those of the author(s) and are not endorsed by BMJ. BMJ disclaims all liability and responsibility arising from any reliance placed on the content. Where the content includes any translated material, BMJ does not warrant the accuracy and reliability of the translations (including but not limited to local regulations, clinical guidelines, terminology, drug names and drug dosages), and is not responsible for any error and/or omissions arising from translation and adaptation or otherwise.

Open access This is an open access article distributed in accordance with the Creative Commons Attribution Non Commercial (CC BY-NC 4.0) license, which permits others to distribute, remix, adapt, build upon this work non-commercially, and license their derivative works on different terms, provided the original work is properly cited, appropriate credit is given, any changes made indicated, and the use is non-commercial. See: http://creativecommons.org/licenses/by-nc/4.0/.

ORCID iD

Kedir Y. Ahmed http://orcid.org/0000-0003-3797-5234

\section{REFERENCES}

1 Black RE, Victora CG, Walker SP, et al. Maternal and child undernutrition and overweight in low-income and middle-income countries. Lancet 2013;382:427-51.

2 Shrimpton R, Victora CG, de Onis M, et al. Worldwide timing of growth faltering: implications for nutritional interventions. Pediatrics 2001;107:E75.

3 WHO. Infant and young child feeding: model chapter for textbooks for medical students and allied health professionals. Geneva, Switzerland: WHO, 2009. 
4 Victora CG, Bahl R, Barros AJD, et al. Breastfeeding in the 21st century: epidemiology, mechanisms, and lifelong effect. Lancet 2016;387:475-90.

5 Sinha B, Chowdhury R, Sankar MJ, et al. Interventions to improve breastfeeding outcomes: a systematic review and meta-analysis. Acta Paediatr 2015;104:114-34.

6 Ahmed KY, Page A, Arora A, et al. Associations between infant and young child feeding practices and acute respiratory infection and diarrhoea in Ethiopia: a propensity score matching approach. PLOS One 2020;15:e0230978.

7 Ogbo FA, Agho K, Ogeleka P, et al. Infant feeding practices and diarrhoea in sub-Saharan African countries with high diarrhoea mortality. PLoS One 2017;12:e0171792.

8 Lee H, Park H, Ha E, et al. Effect of breastfeeding duration on cognitive development in infants: 3-year follow-up study. $J$ Korean Med Sci 2016;31:579-84.

9 Chowdhury R, Sinha B, Sankar MJ, et al. Breastfeeding and maternal health outcomes: a systematic review and meta-analysis. Acta Paediatr 2015;104:96-113.

10 Bhutta ZA, Das JK, Rizvi A, et al. Evidence-based interventions for improvement of maternal and child nutrition: what can be done and at what cost? Lancet 2013;382:452-77.

11 Graziose MM, Downs SM, O'Brien Q, et al. Systematic review of the design, implementation and effectiveness of mass media and nutrition education interventions for infant and young child feeding. Public Health Nutr 2018;21:273-87.

12 Fabrizio CS, Liere M, Pelto G. Identifying determinants of effective complementary feeding behaviour change interventions in developing countries. Matern Child Nutr 2014;10:575-92.

13 Lassi ZS, Rind F, Irfan O, et al. Impact of infant and young child feeding (IYCF) nutrition interventions on breastfeeding practices, growth and mortality in low- and middle-income countries: systematic review. Nutrients 2020;12:722.

14 Shi L, Zhang J. Recent evidence of the effectiveness of educational interventions for improving complementary feeding practices in developing countries. J Trop Pediatr 2011;57:91-8.

15 Tilahun D, Birhanu Z. Effect of community based behavioural change communication intervention to improve neonatal mortality in developing countries: a systematic review. JBI Libr Syst Rev 2011;9:1650-78.

16 Lumbiganon P, Martis R, Laopaiboon M, et al. Antenatal breastfeeding education for increasing breastfeeding duration. Cochrane Database Syst Rev 2016;12:CD006425.

17 WHO. International Code of marketing ofBreast-milk substitutes. Geneva, Swizerland: WHO, 1981.

$18 \mathrm{WHO}$ /UNICEF. Innocenti declaration: on the protection, promotion and support of breastfeeding Florence, Italy, 1990.

19 WHO. Protecting, promoting and supporting breastfeeding in facilities providing maternity and newborn services guideline, 2017. Available: https://www.who.int/nutrition/publications/guidelines/ breastfeeding-facilities-maternity-newborn/en/ [Accessed 04 Feb 2019].

20 UN. Millenium develpment goals and beyond 2015, 2000. Available: https://www.un.org/millenniumgoals/ [Accessed 03 Aug 2020]

21 WHO. Global targets 2025: to improve maternal, infant and young child nutrition. Available: https://www.who.int/nutrition/globaltarget-2025/en/

22 SDG-UN. Transforming our world: the 2030 agenda for sustainable development. New York, USA: UN, 2015.

23 Bhattacharjee NV, Schaeffer LE, Marczak LB, et al. Mapping exclusive breastfeeding in Africa between 2000 and 2017. Nat Med 2019;25:1205-12.

24 Ethiopian Federal Ministry of Health. National strategy for infant and young child feeding. Addis Ababa, Ethiopia: Ethiopian Federal Ministry of Health, 2004

25 Ethiopian Federal Ministry of Health. Health sector transformation plan: 2015/16 - 2019/20 (2008-2012 EFY). Addis Ababa, Ethiopia: Ethiopian Federal Ministry of Health, 2015.

26 Family health department FMoH. National strategy for child survival in Ethiopia. Addis Ababa, Ethiopia, 2005.

27 Ahmed KY, Page A, Arora A, et al. Trends and determinants of early initiation of breastfeeding and exclusive breastfeeding in Ethiopia from 2000 to 2016. Int Breastfeed J 2019;14:40.

28 Ahmed KY, Page A, Arora A, et al. Trends and factors associated with complementary feeding practices in Ethiopia from 2005 to 2016. Matern Child Nutr 2020;16:e12926.

29 USAID. Ethiopia: nutrition profile, 2018. Available: https://www. usaid.gov/sites/default/files/documents/1864/Ethiopia-NutritionProfile-Mar2018-508.pdf
30 Moher D, Shamseer L, Clarke M, et al. Preferred reporting items for systematic review and meta-analysis protocols (PRISMA-P) 2015 statement. Syst Rev 2015;4:1.

31 et alAhmed KY, Ogbo FA, Page A. Effectiveness of infant and young child feeding interventions in Ethiopia: a systematic review and meta-analysis Prospero, 2020. Available: https://www.crd.york.ac. uk/prospero/display_record.php?ID=CRD42020155519

32 WHO, UNICEF. Indicators for assessing infant and young child feeding practices Part 1 definitions. Geneva, Switzerland: WHO, 2008.

33 Johanna Briggs Institute. Joanna Briggs Institute Reviewers'. Adelaide, Australia: Manual The Joanna Briggs Institute, 2019. https://wiki.joannabriggs.org/display/MANUAL/JBI+Reviewer\% $27 \mathrm{~s}+$ Manual

34 Manikam L, Sharmila A, Dharmaratnam A, et al. Systematic review of infant and young child complementary feeding practices in South Asian families: the Pakistan perspective. Public Health Nutr 2018;21:655-68.

35 Dol J, Richardson B, Tomblin Murphy G, et al. Impact of mobile health ( $\mathrm{mHealth}$ ) interventions during the perinatal period for mothers in low- and middle-income countries: a systematic review. JBI Database System Rev Implement Rep 2019;17:1634-67.

36 The Cochrane pregnancy and child birth group. Cochrane Handbook for systematic reviews of interventions. Available: https:// pregnancy.cochrane.org/author-resources-new-reviews [Accessed 02 Mar 2020]

37 Higgins JP, Green S, eds. Cochrane handbook for systematic reviews of interventions. London, UK: A John Wiley \& Sons, Ltd., Publication, 2011

38 Eldridge S, Campbell M, Campbell M. Revised Cochrane risk of bias tool for randomized trials (rob 2.0): additional considerations for cluster-randomized trials, 2016. Available: https://www.unisa. edu.au/contentassets/72bf75606a2b4abcaf7f17404af374ad/rob2$0 \_$cluster_parallel_guidance.pdf

39 Sterne JA, Hernán MA, Reeves BC, et al. ROBINS-I: a tool for assessing risk of bias in non-randomised studies of interventions. BMJ 2016;355:i4919.

40 Altman DG, Bland JM. How to obtain the confidence interval from a $P$ value. BMJ 2011;343:d2090.

41 Altman DG, Bland JM. How to obtain the $\mathrm{P}$ value from a confidence interval. BMJ 2011;343:d2304.

42 Nguyen PH, Kim SS, Tran LM, et al. Early breastfeeding practices contribute to exclusive breastfeeding in Bangladesh, Vietnam and Ethiopia. Matern Child Nutr 2020;16:e13012.

$43 \mathrm{Kim}$ SS, Nguyen PH, Tran LM, et al. Different combinations of behavior change interventions and frequencies of interpersonal contacts are associated with infant and young child feeding practices in Bangladesh, Ethiopia, and Vietnam. Curr Dev Nutr 2020;4:nzz140.

44 Kang Y, Sinamo S, Kim S. Effectiveness of a communitybased participatory nutrition promotion program to improve linear and ponderal growth in children 6 to 24 months of age in rural eastern Ethiopia: a cluster randomized trial. FASEB Journal Conference: Experimental Biology 2015;29:579.14.

45 Baye K, Retta N, Abuye C. Comparison of the effects of conditional food and cash transfers of the Ethiopian productive safety net program on household food security and dietary diversity in the face of rising food prices: ways forward for a more nutritionsensitive program. Food Nutr Bull 2014;35:289-95.

46 Roche ML, Sako B, Osendarp SJM, et al. Community-Based grain banks using local foods for improved infant and young child feeding in Ethiopia. Matern Child Nutr 2017;13:e12219.

47 Gebremariam KT, Zelenko O, Hadush Z, et al. Could mobile phone text messages be used for infant feeding education in Ethiopia? A formative qualitative study. Health Informatics J 2020;26:2614-24.

48 Frongillo EA, Girma M. Understanding the effect of communitybased health and nutrition program on uptake of iron and folic acid supplementation and breastfeeding practices in a pastoralist community in rural Ethiopia. FASEB Journal Conference: Experimental Biology 2017;31.

49 Kang Y, Seo EK, Kim J. Maternal membership of community groups is associated with dietary diversity among children 6 to 12 months of age in rural Ethiopia. FASEB Journal Conference: Experimental Biology 2016;30.

50 Reider K, Mekonnen Y. Effect of timed and targeted counseling (ttC) by peer mothers in changing infant and young child feeding practices among mothers of children 0 to 18 months in four districts in southern Ethiopia. FASEB Journal Conference: Experimental Biology 2013;27.

51 Han YE, Park S, Kim JE, et al. Father engagement in improving infant and young child feeding (IYCF) practices: evidence from a 
clustered randomized controlled trial in Ethiopia (P11-112-19). Curr Dev Nutr 2019;3:nzz048.

52 Beyero M, Reider K, Mekonnen Y. Effect of timed and targeted counseling (ttC) by peer mothers in changing infant and young child feeding practices among mothers of children 0 to 18 months in four districts in Southern Ethiopia. Faseb J 2013;27.

53 Ersino G, Henry CJ, Zello GA. A nutrition education intervention affects the diet-health related practices and nutritional status of mothers and children in a pulse-growing community in Halaba, South Ethiopia. FASEB Journal Conference: Experimental Biology 2017;31

54 Kulkarni S, Frongillo EA, Girma M. Understanding the effect of community-based health and nutrition program on uptake of iron and folic acid supplementation and breastfeeding practices in a pastoralist community in rural Ethiopia. FASEB Journal Conference: Experimental Biology 2017;31.

55 Medhin M, Jirga A, Guyon A. Improving women and children nutrition through targeted capacity building interventions: experience from Ethiopia. Ann Nutr Metab 2013;1:247.

56 Menon P, Nguyen P, Kim S. Scaling up, sustaining, and spinning off: Alive \& thrive's lessons on infant and young child feeding in three countries, and implications for beyond impact: Intervention results from alive \& thrive. Ann Nutr Metab 2017;71:121-2.

57 Faerber E, Brouwer R, Low J, et al. Community-Based Nutrition Education Improves Caregivers' Knowledge of Complementary Feeding in Southern Ethiopia. Curr Dev Nutr 2020;4:979-79.

58 Baker J, Sanghvi T, Hajeebhoy N, et al. Learning from the design and implementation of large-scale programs to improve infant and young child feeding. Food Nutr Bull 2013;34:S226-30.

59 Baker J, Sanghvi T, Hajeebhoy N, et al. Using an evidence-based approach to design large-scale programs to improve infant and young child feeding. Food Nutr Bull 2013;34:S146-55.

60 Piwoz E, Baker J, Frongillo EA. Documenting large-scale programs to improve infant and young child feeding is key to facilitating progress in child nutrition. Food Nutr Bull 2013;34:S143-5.

61 Sanghvi T, Martin L, Hajeebhoy N, et al. Strengthiening systems to support mothers in infant and young child feeding at scale. Food Nutr Bull 2013;34:S156-68.

62 Alemu F, Mecha M, Medhin G. Impact of permagarden intervention on improving fruit and vegetable intake among vulnerable groups in an urban setting of Ethiopia: a quasi-experimental study. PLoS One 2019;14:e0213705

63 Argaw A, Bouckaert KP, Wondafrash M, et al. Effect of fish-oil supplementation on breastmilk long-chain polyunsaturated fatty acid concentration: a randomized controlled trial in rural Ethiopia. Eur J Clin Nutr 2021;75:809-16.

64 Ayalew CA, Belachew T. Effect of complementary feeding behaviour change communication delivered through community-level actors on infant growth and morbidity in rural communities of West Gojiam zone, Northwest Ethiopia: a cluster-randomized controlled trial. Matern Child Nutr 2021;17:e13136.

65 Cherkos TM, Hailemichael T, Sinamo S. Role of nutrition education to overcome food taboos and improve iron tablets demand during pregnancy in Ethiopia: Wonchi district. Ann Nutr Metab 2013;1:1738.

66 Donato K, McConnell M, Han D, et al. Behavioural insights to support increased consumption of quality protein maize by young children: a cluster randomised trial in Ethiopia. BMJ Glob Health 2020;5.

67 Kang Y, Kim S, Sinamo S, et al. Effectiveness of a communitybased nutrition programme to improve child growth in rural Ethiopia: a cluster randomized trial. Matern Child Nutr 2017;13:10.1111/mcn.12349.

68 Samuel A, Brouwer ID, Feskens EJM, et al. Effectiveness of a program intervention with Reduced-Iron multiple micronutrien powders on iron status, morbidity and growth in young children in Ethiopia. Nutrients 2018;10:1508.

69 Argaw A, Huybregts L, Wondafrash M, et al. Neither n-3 LongChain PUFA Supplementation of Mothers through Lactation nor of Offspring in a Complementary Food Affects Child Overall or SocialEmotional Development: A 2 × 2 Factorial Randomized Controlled Trial in Rural Ethiopia. J Nutr 2019;149:505.

70 Argaw A, Wondafrash M, Bouckaert KP, et al. Effects of n-3 long-chain PUFA supplementation to lactating mothers and their breastfed children on child growth and morbidity: a $2 \times 2$ factorial randomized controlled trial in rural Ethiopia. Am J Clin Nutr 2018;107:454

71 Omer AM, Haile D, Shikur B, et al. Effectiveness of a nutrition education and counselling training package on antenatal care: a cluster randomized controlled trial in Addis Ababa. Health Policy Plan 2020;35:i65-75.
72 Fenn B, Bulti AT, Nduna T, et al. An evaluation of an operations research project to reduce childhood stunting in a food-insecure area in Ethiopia. Public Health Nutr 2012;15:1746-54.

73 Demilew YM, Alene GD, Belachew T. Effect of guided counseling on dietary practices of pregnant women in West Gojjam zone, Ethiopia. PLoS One 2020;15:e0233429.

74 Baxter JAB, Barac R, Davidson M. Evaluating programmatic effectiveness and implementation: an assessment of factors affecting change in the practice of exclusive breastfeeding in Ethiopia and Mali. FASEB Journal Conference: Experimental Biology 2016;30.

75 Berti PR, Mildon A, Siekmans K, et al. An adequacy evaluation of a 10-year, four-country nutrition and health programme. Int $J$ Epidemiol 2010;39:613-29.

76 Buchanan SE, Pose B. Improving child survival through behavioral change and community engagement: the Farta, Ethiopia child survival project. Int $J$ Health Promot Educ 2012;50:145-58.

77 Callaghan-Koru JA, Estifanos AS, Sheferaw ED, et al. Practice of skin-to-skin contact, exclusive breastfeeding and other newborn care interventions in Ethiopia following promotion by facility and community health workers: results from a prospective outcome evaluation. Acta Paediatr 2016;105:e568-76.

78 Carnell MA, Dougherty L, Pomeroy AM, et al. Effectiveness of scaling up the 'three pillars' approach to accelerating MDG 4 progress in Ethiopia. J Health Popul Nutr 2014;32:549-63.

79 Kim SS, Rawat R, Mwangi EM, et al. Exposure to large-scale social and behavior change communication interventions is associated with improvements in infant and young child feeding practices in Ethiopia. PLoS One 2016;11:e0164800.

80 Kung'U JK, Pendame R, Ndiaye MB, et al. Integrating nutrition into health systems at community level: impact evaluation of the community-based maternal and neonatal health and nutrition projects in Ethiopia, Kenya, and Senegal. Matern Child Nutr 2018;14 Suppl 1

81 Mulualem D, Henry CJ, Berhanu G, et al. The effectiveness of nutrition education: applying the health belief model in child-feeding practices to use pulses for complementary feeding in southern Ethiopia. Ecol Food Nutr 2016;55:308-23.

82 Negash C, Belachew T, Henry CJ, et al. Nutrition education and introduction of broad bean-based complementary food improves knowledge and dietary practices of caregivers and nutritional status of their young children in Hula, Ethiopia. Food Nutr Bull 2014;35:480-6.

83 Villadsen SF, Negussie D, GebreMariam A, et al. Antenatal care strengthening for improved health behaviours in Jimma, Ethiopia, 2009-2011: an effectiveness study. Midwifery 2016;40:87-94.

84 Bahru BA, Jebena MG, Birner R, et al. Impact of Ethiopia's productive safety net program on household food security and child nutrition: a marginal structural modeling approach. SSM Popul Health 2020;12:100660.

85 Karim AM, Admassu K, Schellenberg J, et al. Effect of Ethiopia's Health Extension Program on Maternal and Newborn Health Care Practices in 101 Rural Districts: A Dose-Response Study. PLoS One 2013;8:e65160.

86 Karim AM, Fesseha Zemichael N, Shigute T, et al. Effects of a community-based data for decision-making intervention on maternal and newborn health care practices in Ethiopia: a doseresponse study. BMC Pregnancy Childbirth 2018;18:359.

87 Wereta T, Betemariam W, Karim AM, et al. Effects of a participatory community quality improvement strategy on improving household and provider health care behaviors and practices: a propensity score analysis. BMC Pregnancy Childbirth 2018;18:364.

88 Kang Y, Suh YK, Debele L, et al. Effects of a community-based nutrition promotion programme on child feeding and hygiene practices among caregivers in rural eastern Ethiopia. Public Health Nutr 2017;20:1461-72.

$89 \mathrm{Kim} \mathrm{SS}$, Nguyen PH, Yohannes Y, et al. Behavior change interventions delivered through interpersonal communication, agricultural activities, community mobilization, and mass media increase complementary feeding practices and reduce child stunting in Ethiopia. J Nutr 2019;149:1470-81.

90 Tariku B, Whiting SJ, Mulualem D, et al. Application of the health belief model to teach complementary feeding messages in Ethiopia. Ecol Food Nutr 2015;54:572-82.

91 Abdulahi M, Fretheim A, Argaw A, et al. Breastfeeding education and support to improve early initiation and exclusive breastfeeding practices and infant growth: a cluster randomized controlled trial from a rural Ethiopian setting. Nutrients 2021:13:1204.

92 Abiyu C, Belachew T. Effect of complementary feeding behavior change communication delivered through community-level actors on dietary adequacy of infants in rural communities of West Gojjam 
Zone, Northwest Ethiopia: A cluster-randomized controlled trial. PLoS One 2020;15:e0238355.

93 Abiyu C, Belachew T. Effect of complementary feeding behavior change communication delivered through community-level actors on the time of initiation of complementary foods in rural communities of West Gojjam zone, Northwest Ethiopia: a clusterrandomized controlled trial. BMC Pediatr 2020;20:509.

94 Muluye SD, Lemma TB, Diddana TZ. Effects of nutrition education on improving knowledge and practice of complementary feeding of mothers with 6- to 23-Month-Old children in daycare centers in Hawassa town, southern Ethiopia: an Institution-Based randomized control trial. J Nutr Metab 2020;2020:1-10.

95 Passarelli S, Ambikapathi R, Gunaratna NS, et al. A chicken production intervention and additional nutrition behavior change component increased child growth in Ethiopia: a cluster-randomized trial. J Nutr 2020;150:2806-17.

96 Teshome GB, Whiting SJ, Green TJ, et al. Scaled-up nutrition education on pulse-cereal complementary food practice in Ethiopia: a cluster-randomized trial. BMC Public Health 2020;20:1437.

97 Warren AM, Frongillo EA, Nguyen $\mathrm{PH}$, et al. Nutrition intervention using behavioral change communication without additional material inputs increased expenditures on key food groups in Bangladesh. $J$ Nutr 2020;150:1284-90.

98 Akhter A, Hoddinott J, Roy S. Food transfers, cash transfers, behavior change communication and child nutrition: evidence from Bangladesh. Food Laws, 2019.

99 Affleck W, Pelto G. Caregivers' responses to an intervention to improve young child feeding behaviors in rural Bangladesh: a mixed method study of the facilitators and barriers to change. Soc Sci Med 2012;75:651-8.

100 Avula R, Menon P, Saha KK, et al. A program impact pathway analysis identifies critical steps in the implementation and utilization of a behavior change communication intervention promoting infant and child feeding practices in Bangladesh. J Nutr 2013:143:2029-37.
101 Ogbo FA, Akombi BJ, Ahmed KY, et al. Breastfeeding in the Community-How can Partners/Fathers help? A systematic review. Int J Environ Res Public Health 2020;17:413.

102 Sanghvi T, Seidel R, Baker J. Using behavior change approaches to improve complementary feeding practices. Matern Child Nutr 2017;13:e12406.

103 Health EFMo. National nutrition strategy, 2008

104 WHO/UNICEF. Infant and young child feeding, 2018. Available: https://www.who.int/en/news-room/fact-sheets/detail/infant-andyoung-child-feeding [Accessed 08 Apr 2019].

105 Patil S, Nimmagadda S, Gopalakrishnan L, et al. Mobile technology integrated into a large-scale nutrition program enables AgeAppropriate home visits and counseling for mothers of infants in India. Curr Dev Nutr 2020;4:886-86.

106 Flax VL, Negerie M, Ibrahim AU, et al. Integrating group counseling, cell phone messaging, and participant-generated songs and Dramas into a microcredit program increases Nigerian women's adherence to international breastfeeding recommendations. J Nutr 2014;144:1120-4

107 Lee SH, Nurmatov UB, Nwaru BI, et al. Effectiveness of mHealth interventions for maternal, newborn and child health in low- and middle-income countries: systematic review and meta-analysis. $J$ Glob Health 2016;6:010401-01.

108 Downs SM, Sackey J, Kalaj J, et al. An mHealth voice messaging intervention to improve infant and young child feeding practices in Senegal. Matern Child Nutr 2019;15:e12825.

109 Bezner Kerr R, Dakishoni L, Shumba L, et al. "We grandmothers know plenty": breastfeeding, complementary feeding and the multifaceted role of grandmothers in Malawi. Soc Sci Med 2008;66:1095-105.

110 Negin J, Coffman J, Vizintin P, et al. The influence of grandmothers on breastfeeding rates: a systematic review. BMC Pregnancy Childbirth 2016;16:91.

111 WHO/UNICEF. Indicators for assessing infant and young child feeding practices: definitions and measurment methods. Geneva: WHO/UNICEF, 2021. 